\title{
Geociências
}

\section{Jarina: o marfim das biojóias da Amazônia}

\author{
Marcondes Lima da Costa \\ CG/UFPa e Pesquisador CNPq \\ E-mail:mlc@ufpa.br
}

\author{
Suyanne Flávia Santos Rodrigues \\ CG/UFPa e EN/UFPa \\ E-mail:suyanneflavia@hotmail.com
}

Helmut Hohn

Autônomo

E-mail:hhohn@zipmail.com.br

\section{Resumo}

A palmeira jarina (Phytelephas macrocarpa) é endêmica da Amazônia, onde se desenvolve sobre antigas planícies de inundação, cujos sedimentos são constituídos por quartzo, minerais de argila 2:1 e feldspatos, constituindo solos férteis e pouco ácidos a neutros. As sementes dessa palmeira são incluídas entre as gemas orgânicas raras. Devido a sua cor e brilho, as sementes são comparadas ao marfim animal, apesar da baixa dureza e baixa densidade, sendo empregadas na manufatura de biojóias e artefatos. Esses produtos são bem aceitos comercialmente devido às sementes serem susceptíveis a mudança de coloração e outros melhoramentos. Infelizmente, as jóias não apresentam vida longa, pois as sementes podem sofrer ataque de microorganismos entre 5 e 10 anos. Se houver uma política adequada para cadeia produtiva das sementes de jarina, a mesma poderá se tornar de grande importância para o desenvolvimento da região Amazônica, ao criar novas oportunidades de trabalho e agregação de valor aos produtos. No entanto fazse necessário um especial cuidado para evitar exploração inadequada das sementes para assegurar a preservação da espécie.

Palavras-chave: Jarina, Amazônia, marfim-vegetal, sementes, gema orgânica, Phytelephas macrocarpa, biojóias.

\begin{abstract}
The jarina palm tree (Phytelephas macrocarpa) is endemic of the Amazon region growing in older flood plains constituted by quartz, 2:1 clay-minerals and feldspars. The soils are fertile and slightly acid to neutral. The jarina seeds can be included among the rare organic gems. Because of its color and luster the seeds are compared to animal ivory in spite of its lower hardness and lower density. They are largely employed in the manufacture of bio-jewels and artifacts. The products are commercially well accepted because the seeds support coloration change and other improvements. However, the jewels do not last very long because the seeds tend to be destroyed by the action of microorganisms within 5 to 10 years. By means of an adequate policy the productive chain of jarina seeds may turn to be of great importance for the development of the Amazon region by creating new job opportunities and by aggregating value to the products. However, special care has to be taken to avoid inadequate exploration of the seeds in order to assure the preservation of the species.
\end{abstract}

Keywords: Jarina, Amazon region, vegetable-ivory, seeds, organic gem, Phytelephas macrocarpa, bio-jewels. 


\section{Introdução}

Jarina é o nome da semente da palmeira de igual nome, a Phytelephas macrocarpa $($ Phyto $=$ planta e elephas $=$ elefante), encontrada no sudoeste e oeste da região amazônica, estendendo-se além das fronteiras brasileiras. Essa semente, em especial a sua amêndoa, que há muito tempo chama atenção por suas propriedades físicas similares às do marfim, é conhecida há mais de um século como marfim vegetal, sendo, hoje, considerada como substituto à altura do marfim animal. Sobre a produção na Amazônia ainda no início do século XX assim reporta Andrade (1937): “O Juruá já attingiu a exportação de $100.000 \mathrm{kgs}$, annualmente. Se o transporte fosse fácil, a exportação poderia subir a mais de $1.000 .000 \mathrm{kgs}$. O rio Envira, sobretudo, é privilegiado em matéria de jarina”. A jarina, era na época, empregada no fabrico de botões, tendo sido substituída pelo plástico logo após seu surgimento. No Brasil a última fábrica fechou nos anos 70. A jarina em países vizinhos, como Peru, Colômbia e Equador, é empregada na produção de artefatos diversos e bijuterias, geralmente, bem aceitas no mercado internacional, por conta do fino acabamento. A jarina sempre foi apreciada pelos povos dos barrancos de rios, devido a sua palha resistente utilizada em coberturas, seus frutos como alimento e, quando secos, para o fabrico de carvão, sendo aplicado nos interiores de panelas de barro para lubrificá-los, um precursor do teflon. A palmeira também fornece palmito.

Nos anos 80, a jarina começou a ressurgir através de trabalhos de artistas isolados, no Acre, Amazonas e Rondônia, a bom exemplo o ourives César Farias, em Rio Branco, Acre, que começa a procurar nas sementes e madeiras a combinação ideal com os metais nobres, principalmente com a prata. Nos anos 90, o primeiro autor do presente artigo, participou do programa de implantação do Pólo Joalheiro do Pará e, após ter organizado cursos de especialização em gemologia na UFPa, onde as sementes em bijuterias, incluindo a jarina, foram temas de monografias, apresentou e ressaltou o seu potencial gemológico e ape- lo ecológico. Contudo a jarina precisou de apenas 8 anos para sair de sua aparente dormência de pouca importância (a semente apresenta elevada dormência natural) e retomar o seu lugar, agora um produto mais nobre, como uma gema orgânica.

\section{A palmeira}

A palmeira jarina apresenta a seguinte taxonomia: Família: Palmae; Subfamília: Phytelephantoidae; Gênero: Phytelephas; Espécie: $P$. macrocarpa Ruiz \& Pavon (Henderson et al., 1995). Ressalta-se que, tanto o gênero, quanto à espécie, têm os seguintes sinônimos: Elephantusia macrocarpa Ruiz \& Pavon, Willd, Phytelephas microcarpa Ruiz \& Pavon, Yarina microcarpa Ruiz \& Pavon, O. F. Cook (Ferreira, 2006).

A Phytelephas macrocarpa tem, nas terras do Estado do Acre, as seguintes características botânicas e ecológicas (Ferreira, 2006):

"Estipe: solitário ou raramente cespitoso; subterrâneo ou aéreo com até 1,5 $m$ de comprimento levemente inclinado, com cicatrizes foliares salientes, coberto com bainhas de folhas persistentes no ápice, às vezes, envolvidas por fibras finas. Folhas: 14 a 17; pecíolo e bainha com 1,4 $m$ de comprimento, a bainha fibrosa; raque 4,19 a 4,2 de comprimento; 57 ou 58 pinas lineares em cada lado da folha, mais ou menos arranjadas e dispostas em um mesmo plano. Inflorescência: fortemente dimorfa; inflorescência estaminada e pistilada intrafoliar. Flores estaminadas sésseis, densamente arranjadas na raque; sépalas e pétalas reduzidas em obscuras bractéolas. Frutos: com até $9 \mathrm{~cm}$ de comprimento, formando uma massa mais ou menos globosa no ápice da raque; 4 a 6 vezes angulosos- obdeltóide, com a superfície apical lenhosa. Sementes: várias por fruto".

A jarina (Figura 1.a) é uma palmeira de porte pequeno, alcançando até 5 metros de altura, acaule ou de caule curto, tronco grosso com numerosas raízes adventícias e flores de forte perfume (Fer- reira, 2004). Produz cachos (Figura 1.b) de frutos drupáceos (Figura 1.c), que contêm até 9 sementes (Figura 1.d). O crescimento da palmeira jarina é lento e uma árvore que apresente tronco de dois metros de altura tem pelo menos de 35 a 40 anos de idade. É comum encontrar indivíduos com mais de 100 anos de idade. É possível que os exemplares da Praça Plácido de Castro, em Rio Branco, no Estado do Acre, com tronco acima de $1 \mathrm{~m}$ tenham mais de 30 anos. Segundo Ferreira (2004), a germinação ocorre em 3 ou 4 anos, no entanto, em cultivo de quintal, na cidade de Rio Branco, Acre, observou-se que a semente germinou em um ano. A frutificação ocorre a partir do sétimo ano (Ferreira, 2004), porém, no experimento de quintal mencionado anteriormente, esta ocorreu a partir do quinto ano.

\subsection{Distribuição geográfica e ambiente geológico}

A palmeira jarina é endêmica do sudoeste e oeste da Amazônia. No Brasil é encontrada nos Estados de Rondônia, Acre e Amazonas e, também, na Bolívia, Peru, Colômbia e no Equador, chegando à América Central (Figura 2). Em terras brasileiras, a jarina desenvolve-se espontaneamente nas planícies de inundação, principalmente nas mais antigas, nos vales dos rios de água branca, destacando-se os rios Purus, Juruá e seus afluentes. Formam verdadeiro gregarismo, conhecido como jarinal. As planícies são formadas por sedimentos siltoargilosos, constituídos, além de quartzo, por minerais de argila 2:1 (esmectitas, illitas e micas brancas) e feldspatos. São sedimentos ricos em $\mathrm{SiO}_{2}$ e $\mathrm{Al}_{2} \mathrm{O}_{3}$, contendo, ainda, valores significativos de $\mathrm{K}_{2} \mathrm{O}, \mathrm{MgO}$ e $\mathrm{CaO}$. São pouco ácidos e relativamente férteis (Almeida, 2005). Também se desenvolvem ao longo de encostas de vales úmidos. São solos do tipo argissolos e cambissolos eutróficos. A jarina é uma palmeira umbrófila e, nessas planícies, está associada com o mulateiro, Calycolphylum spruceanum, típico desse ambiente, e bambus, entre outras espécies arbóreas e de palmae. 


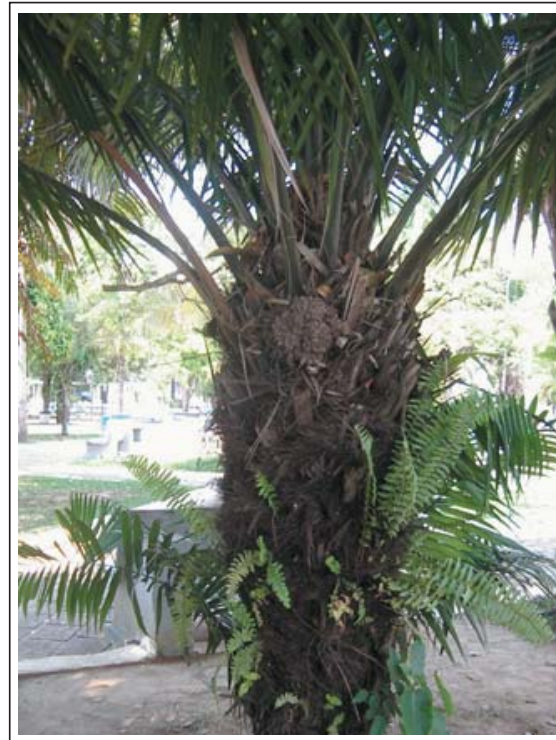

(a)

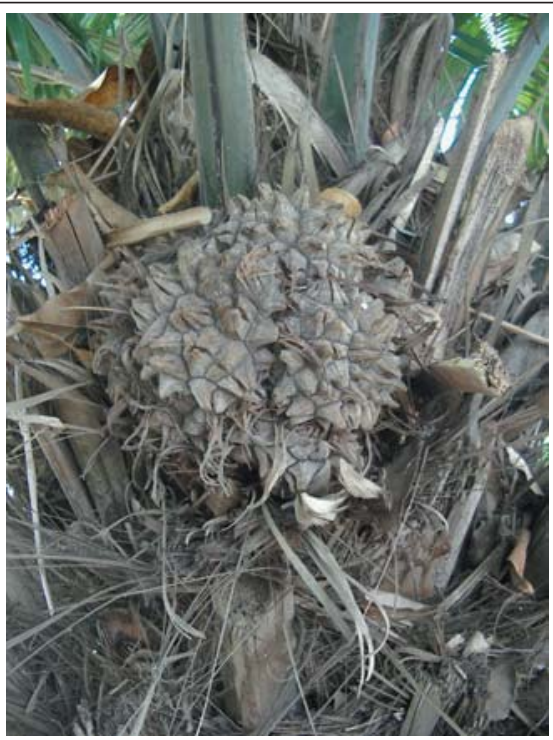

(b)

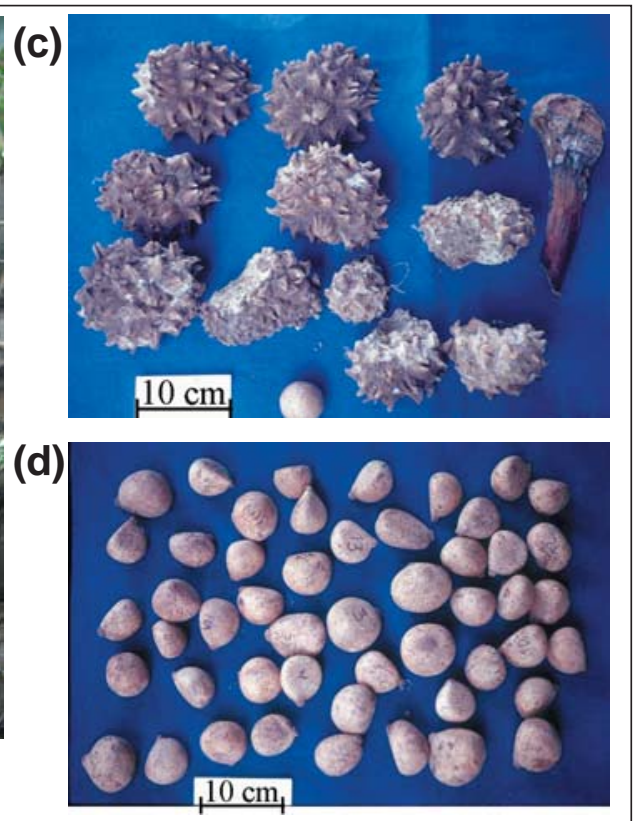

Figura 1 - (a) Palmeira jarina localizada na Praça Plácido de Castro no centro de Rio Branco, Acre; (b) Cacho de frutos da palmeira jarina; (c) Frutos da palmeira jarina; (d) Sementes da palmeira jarina ainda com a casca mais externa.

\section{A semente e a amêndoa: o marfim vegetal}

A palmeira frutifica uma vez ao ano, desenvolvendo de 6 a 8 cachos, que atingem o tamanho de uma cabeça humana adulta e chegam a pesar $10 \mathrm{~kg}$. Os cachos de jarina tipo Acre são formados por até 9 frutos ou ouriços, os quais contêm em média 3 a 4 sementes. A semente tem um tegumento (casca) composto por três camadas, sendo a mais interior fortemente fixada à amêndoa e, em geral, preservada pelos artesãos, pois permite desenvolver belos trabalhos. A semente com casca tem forma triangulóide, com as três faces angulosas-obdeltóides, com superfície apical abaulada. A amêndoa guarda essa morfologia, embora tenda a apresentar um maior arredondamento. O núcleo normalmente é oco. O comprimento varia de 48,5 a $80 \mathrm{~mm}$, a largura maior de 43 a $87,7 \mathrm{~mm}$ e a menor de $38,7 \mathrm{a}$ $83 \mathrm{~mm}$. A massa oscila entre 10 e $20 \mathrm{~g}$, normalmente de 14 a $18 \mathrm{~g}$, e a perda de massa por desidratação é de 1 a $4,5 \%$. Quando sem casca, as sementes pesam de $10 \mathrm{a} 14 \mathrm{~g}$. A perda de massa por desidratação não causa danos, como retração e fissuramento, na amêndoa.
Na jarina, o embrião ou amêndoa ocupa, praticamente, todo o interior da semente, que é um albúmen (endosperma) córneo, de constituição hemicelulose (polímero de pentoses), geralmente encontrada na terceira camada celular do endosperma. A cavidade central é irregular, ligeiramente trapezoedróide (Figura 3.a). Essa retração fica restrita a parte interior da amêndoa. A massa da semente madura (endosperma) é de cor branca com brilho característico muito semelhante ao marfim obtido de animais. A amêndoa é conhecida, internacionalmente, como ivory nut (inglês), tagua nut ou tagua (em áreas de influência norte-americanas), corozo (em áreas de influência britânicas), Steinnuss (alemão), binroji (japonês) e coquilla, nuez de tagua ou yarina (espanhol).

\subsection{Características físicas e químicas}

A amêndoa tem a cor branca marfínica, leitosa, o brilho sedoso do marfim, a dureza mediana (2,5 na escala de Mohs), igual índice de refração $(1,54)$, densidade $(1,43)$, no entanto mais baixa, quando comparada ao marfim de origem animal, não quebradiça, mas sensível ao

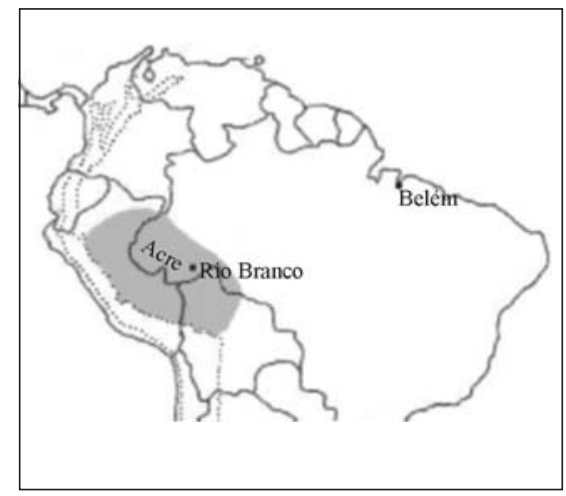

Figura 2 - Distribuição geográfica (área cinza-escura) da palmeira jarina (Phytelephas macrocarpa) na América do Sul: Peru, Bolívia e Brasil (Acre, Amazonas e Rondônia). A área pontilhada indica a ocorrência mais restrita, zona da borda da cordilheira andina e com características distintas daquelas encontradas no Brasil. Modificado de Henderson et al. (1995).

calor e a certos fungos e insetos, principalmente a partir da cavidade central. Ao contrário do marfim animal deixa-se tingir facilmente. É formada de celulose (um carboidrato muito resistente, $\mathrm{C}_{6} \mathrm{H}_{10} \mathrm{O}_{5}$ ), segundo Leite (1993). É amorfa, enquanto o marfim animal é constituído por fosfatos e carbonatos de cálcio e magnésio, parcialmente cristalinos. Fluoresce levemente em tom azul-violáceo (Leite, 1993). 
A amêndoa é formada por finas camadas concêntricas (Figura 3.a) interrompidas apenas na região de influência do hilo. São camadas submilimétricas (Figura 3.b), alternando quase maciças com fibras, mais espessas. No todo, a amêndoa é fibro-radial e as fibras são perfeitamente delineáveis em imagens de MEV. Embora a amêndoa seja amorfa à difração de raios $\mathrm{X}$, apresenta cristalitos de aluminossilicatos de $\mathrm{Ca}$-K identificados por MEV/SED. A semente, no geral, tem $\mathrm{SiO}_{2}$ como o principal componente inorgânico, com vestígios de P(Tabela 1).

\section{Beneficiamento e principais produtos}

A coleta é feita na mata, no período de janeiro a junho, tanto do chão ou pela retirada dos cachos. $\mathrm{O}$ beneficiamento consiste de secagem da semente ao sol ou mesmo em estufa. Em seguida, faz-se o lixamento para remoção da casca interna, conforme o desejo do cliente, e, posteriormente, o polimento.

Da mesma forma, como muitos minerais-gemas e gemas orgânicas, a amêndoa de jarina, já incluída como gema orgânica, deixa-se modificar, principalmente, em sua coloração, através de tingimento com corantes sintéticos e naturais (Farias, 2005), de cozimento e/ou imersão em óleos e através da ação térmica, como pirógrafo e aquecimento, e, ainda, através de amadurecimento controlado e envelhecimento, graças a sua microporosidade. As tonalidades obtidas não mascaram a natureza marfínica da jarina e têm tido grande aceitação do público consumidor. Para o uso em biojóias, além dos melhoramentos citados anteriormente, normalmente as sementes são furadas e também são formatadas em fatias (slabs), cascalho e canutilhos ou tubinhos.

A amêndoa da jarina tem encontrado ampla aplicação em biojóias, miniesculturas e adereços em geral (Figura 4), sendo a mais expressiva, atualmente, as biojóias (colares, pulseiras, brincos e anéis). Ela é combinada com outras sementes como açaí, paxiúba e paxiubinha,

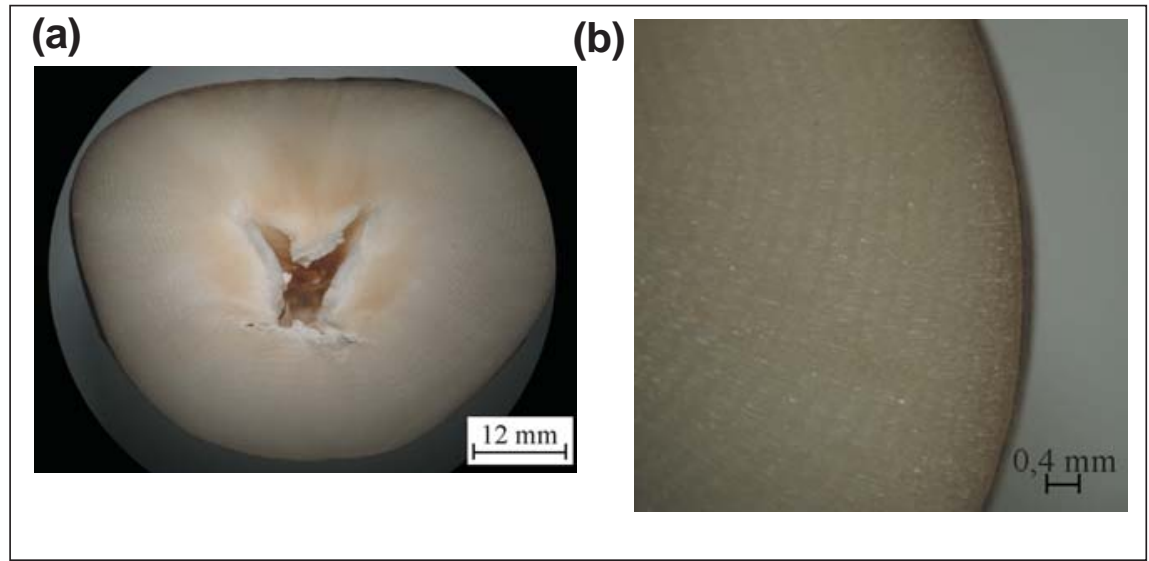

Figura 3 - (a) Interior de uma amêndoa de jarina mostrando as camadas concêntricas e com feições fibro-radiais; (b) Detalhe das camadas concêntricas e fibro-radiais. Imagem obtida com microscópio óptico.

Tabela 1 - Resultados de análises químicas (\% em peso) efetuadas em semente de jarina. As análises químicas foram efetuadas por via úmida (gravimetria, EDTA e espectrocolorimetria) nos laboratórios do Centro de Geociências/UFPA.

\begin{tabular}{c|c|c|c|c|c|c}
\hline Amostra & $\mathrm{SiO}_{2}$ & $\mathrm{Al}_{2} \mathrm{O}_{3}$ & $\mathrm{Fe}_{2} \mathrm{O}_{3}$ & $\mathrm{TiO}_{2}$ & $\mathbf{P}_{2} \mathrm{O}_{5}$ & $\begin{array}{c}\text { Perda ao } \\
\text { fogo (PF) }\end{array}$ \\
\hline $\mathrm{JÁ}-01$ & 1,67 & $<0,10$ & $<0,01$ & $<0,03$ & 0,24 & 99,05 \\
\hline
\end{tabular}

madeiras e, mais recentemente, com prata e ouro (Farias, 2005). A combinação com minerais tem tido sucesso, mesmo sabendo da sobrevida mais curta da semente, variando entre 5 e 10 anos, em relação à sobrevida do mineral, que pode atingir milhões de anos. No Equador e em outros países vizinhos e da América Central, a jarina é empregada, principalmente, em miniesculturas, retratando animais da fauna regional. São trabalhos com grande aceitação no mercado internacional. No Brasil, as biojóias estão sendo produzidas, principalmente, nos Estados do Pará (Pólo Joalheiro), Amazonas (ofertada em shopping centers e no aeroporto internacional) e Acre, onde o mercado, nos últimos anos, vem se desenvolvendo rapidamente.

\section{Conclusões}

A jarina deve ser vista como uma gema orgânica, genuinamente da região Amazônica, estendendo-se além das fronteiras brasileiras. Seria rara, como são as gemas inorgânicas e mesmo orgânicas, mas tão-somente por ser apenas tí- pica de uma única região, o sudoeste da Amazônia, a sua única “jazida”._No entanto, a jarina pode ser cultivada, correspondendo no mundo de gemas minerais como uma "gema sintetizada". Suas jóias são bonitas e com preços acessíveis, mas, infelizmente, não têm vida longa.

A natureza endêmica da jarina mostra sua forte relação com as planícies de inundação de rios de água branca do sudoeste da Amazônia (Estados do Acre e Amazonas), as quais são formadas por sedimentos fluviais imaturos e férteis.

A cadeia produtiva é grande e a agregação de valor é enorme, pois uma semente coletada sai no campo ao custo de $\mathrm{R} \$ 0,02$ e um pequeno chaveiro entalhado em uma única semente é comercializado, em Rio Branco, a R\$ 17,00, ou seja, um fator de agregação de valor superior a 500 vezes.

A jarina é, provavelmente, a semente mais nobre da Amazônia para uso em biojóias. Sua exploração se enquadra na política de desenvolvimento sustentável, entra como um substituto adequado 
ao marfim animal, podendo vir a coibir o comércio desses materiais. No entanto a exploração em larga escala da semente da jarina, sem um acompanhamento de manejo e mesmo de cultivo, pode trazer danos incalculáveis à reprodução e continuidade dos jarinais, cujo ambiente geológico é muito efêmero, restrito e frágil. Uma política de incentivos para o desenvolvimento de novos produtos, de conservação (longevidade) da jarina, e de combinação desta com pedras e gemas, poderá criar uma cadeia produtiva de alta qualidade e grande diferencial humano e de design, criando e projetando uma verdadeira atividade nobre na Amazônia.

\section{Agradecimentos}

Ao Basa pelo primeiro apoio financeiro, a Florestar (Família Profetto), a Comuflor, a NaturArte de Socorro Freias e a César Farias.

\section{Referências bibliográficas}

ALMEIDA, H. D. F. Mineralogia, geoquímica, fertilidade e origem dos sedimentos de praia (Barra em Pontal) das bacias dos rios Purus e Juruá no estado do Acre. Belém: Centro de Geociências/ Universidade Federal do Pará, 2005.153p. (Dissertação de Mestrado).

ANDRADE, O. Amazônia, esboço histórico, geographia physica, geographia humana e ethnographia do rio Juruá. Maceió: Off. Graph. Da Casa Ramalho, 1937. 160p.

FARIAS, C. A Peleja do Zé Jarina e técnicas de produção de biojóias em sementes da Amazônia. Rio Branco: Fundação Elias Mansour, 2005. 43p.

FERREIRA, M. G. R. Jarina, o marfim vegetal. Internet: http : // www.cpafro.embrapa.br/ embrapa / Artigos/jarina.html, 2004. 1p.

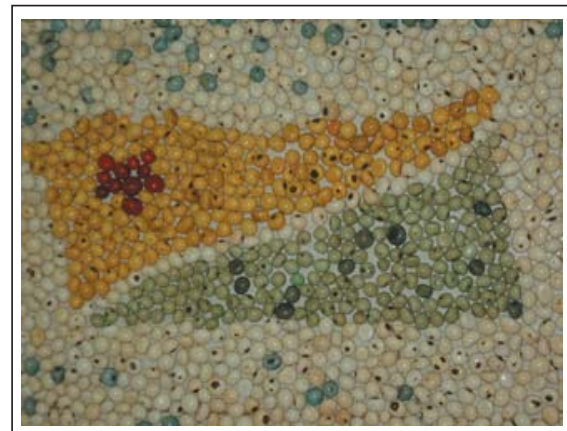

(a)

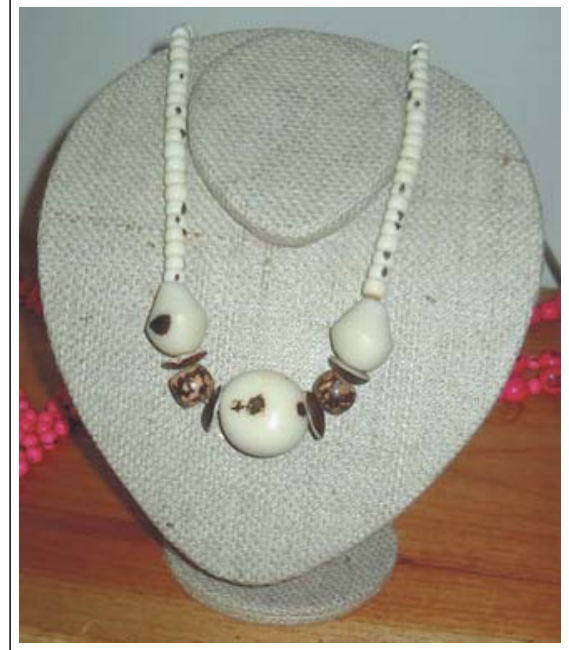

(c)

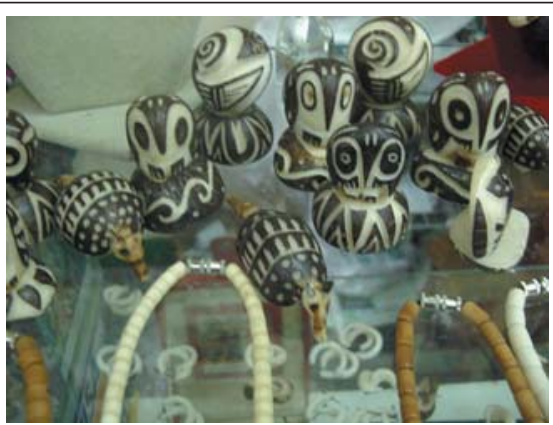

(b)

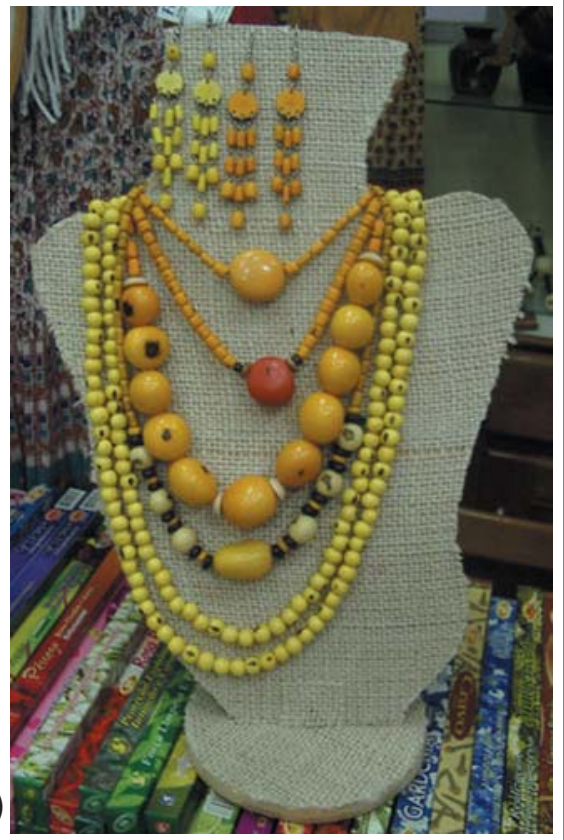

Figura 4- (a) Sementes de jarina tingidas em diferentes tonalidades e organizadas segundo a bandeira do estado do Acre. Oficina Florestar em Rio Branco, Acre; (b) Miniesculturas executadas em sementes de jarina tipo Acre (Phytelephas macrocarpa), produzidas pela Florestar e disponíveis em sua loja no Mira Shopping em Rio Branco, Acre; (c) Colar formado pela combinação de sementes de jarina, em diversas formas e, ainda, como pingente do mesmo colar, com outras sementes da Amazônia. Casa do Artesão em Rio Branco, Acre; (d) Biojóias formadas pela combinação de sementes de jarina tingidas com outras sementes da Amazônia, loja Florestar em Rio Branco, Acre.

FERREIRA, E. L. Manual das palmeiras do Acre, Brasil. Rio Branco: Instituto Nacional Pesquisas/ Universidade Federal do Acre, 2006. 212p.

HENDERSON.A., GALENO. G., BERNAL, R. Field guide to the palms of the Americas,

$3^{\circ}$ ed. New Jercey: Princeton University Press, 1995. 236 a 238p. 352p.

LEITE, W. M. Marfim vegetal (Jarina). São Paulo: IBGM, 1993 (Nota Técnica).

Artigo recebido em 16/05/2006 e aprovado em 29/11/2006. 